\title{
Experimental Investigation of the Relationship between the P-Wave Velocity and the Mechanical Properties of Damaged Sandstone
}

\author{
Qi-Le Ding ${ }^{1}$ and Shuai-Bing Song ${ }^{2}$ \\ ${ }^{1}$ School of Mines, State Key Laboratory of Coal Resources and Safe Mining, China University of Mining and Technology, \\ Xuzhou 221116, China \\ ${ }^{2}$ State Key Laboratory for Geomechanics and Deep Underground Engineering, China University of Mining and Technology, \\ Xuzhou 221116, China \\ Correspondence should be addressed to Qi-Le Ding; leqiding@hotmail.com
}

Received 4 August 2016; Revised 25 October 2016; Accepted 13 November 2016

Academic Editor: Giorgio Pia

Copyright (C) 2016 Q.-L. Ding and S.-B. Song. This is an open access article distributed under the Creative Commons Attribution License, which permits unrestricted use, distribution, and reproduction in any medium, provided the original work is properly cited.

To obtain an improved and more accurate understanding of the relationship between the P-wave velocity and the mechanical properties of damaged sandstone, uniaxial compression tests were performed on sandstone subjected to different high-temperature treatments or freeze-thaw (F-T) cycles. After high-temperature treatment, the tests showed a generally positive relationship between the P-wave velocity and mechanical characteristics, although there were many exceptions. The mechanical properties showed significant differences for a given P-wave velocity. Based on the mechanical tests after the F-T cycles, the mechanical properties and P-wave velocities exhibited different trends. The UCS and Young's modulus values slightly decreased after 30, 40, and 50 cycles, whereas both an increase and a decrease occurred in the P-wave velocity. The UCS, Young's modulus, and P-wave velocity represent different macrobehaviors of rock properties. A statistical relationship exists between the P-wave velocity and mechanical properties, such as the UCS and Young's modulus, but no mechanical relationship exists. Further attention should be given to using the P-wave velocity to estimate and predict the mechanical properties of rock.

\section{Introduction}

High-temperature treatments and freeze-thaw (F-T) cycles are important factors that can degrade physical and mechanical properties. Rock masses involved in the underground storage of petroleum and natural gas, the utilization of geothermal resources, and the disposal of radioactive nuclear waste undergo high-temperature processes [1,2]. Najafi et al. [3] demonstrated that rocks in the vicinity of an underground coal gasification panel were subjected to temperatures that exceeded $1,000^{\circ} \mathrm{C}$. Many scholars have obtained valuable research results regarding the physical and mechanical properties of rocks after high-temperature treatments [4-11]. Ferrero and Marini [12] investigated the density of cracks in rocks via microscopic analysis and found that new fractures and cracks increased the porosity. Additionally, the strength, deformation characteristics, and failure modes of sandstone, limestone, and marble subjected to high-temperature treatments have been studied extensively [13-15].

Another factor that causes damage in a rock mass is F$\mathrm{T}$ cycling, which is a deterioration process that frequently occurs in cold climates [16-18]. When water freezes, its volume increases, generating microcracks and inducing stress concentrations in the rock [19]. When the rock thaws, water flows through the micropores and causes the original fractures to expand [20-22]. Previous studies have examined the effects of F-T cycling on the properties of natural rocks, such as the strength, compressibility, porosity, pore size distribution, permeability, and mineral content [23-29].

In engineering projects that involve high-temperature treatments or F-T cycling, the mechanical behavior of the rock must be determined to predict its stability. In the 
past, data were obtained through destructive experiments, such as uniaxial and triaxial tests. However, a number of nondestructive evaluation methods that can determine the preservation state and cause no damage to the rock elements are currently being used [30]. Ultrasonic measurement is one of the most important nondestructive methods applied to rock analysis because it is fast, economical, and easy to apply in field or laboratory studies [31-38]. Previous studies have revealed that the spatial attenuation of ultrasonic waves is a sensitive parameter that offers a more complete view of the state of a rock [39].

The ultrasonic waves that penetrate rocks are generated using an external source and are acquired using a receiver after they pass through the medium. A significant amount of information about the material can be obtained based on the analyses of the processes and parameters coupled with the propagation of the elastic wave inside the rock [40]. The Pwave velocity is determined based on a complex set of material properties, such as the mineral compositions, porosity, pore fluid characteristics, and pore structure [41-43]. Song et al. [44] investigated the P-wave velocity of saturated schist with fractures during a compression test and obtained the relationship between the P-wave velocity and damage levels. Lafhaj et al. [45] obtained a correlation between the ultrasonic wave velocity, porosity, and permeability based on their investigation of seven mortar mixtures with water/cement ratios that varied from 0.3 to 0.6 . Goueygou et al. [46] investigated the relationship between Rayleigh wave velocity at ultrasonic frequencies and the porosity in dry and fully saturated mortars. Byun et al. [47] used a new model that consisted of several elastic moduli and Poisson's ratio to determine rock crack densities using elastic wave velocities. Several researchers have studied the influences of different petrographic characteristics on ultrasonic wave propagation [48-50]. Their results showed interesting relationships between various petrographic parameters (such as crystal size and/or porosity) and the ultrasonic wave propagation velocity.

Previous studies have only provided qualitative results. Quantitative research regarding the relationship between the $\mathrm{P}$-wave velocity and the mechanical characteristics of rocks is limited.

In this paper, damaged sandstone samples were produced using a $400-800^{\circ} \mathrm{C}$ high-temperature treatment or $10-50 \mathrm{~F}$ $\mathrm{T}$ cycles. Ultrasonic and uniaxial compression tests were performed on the damaged sandstone; thus, the relationship between the uniaxial compressive strength (UCS), Young's modulus, and P-wave velocity was obtained. This information offers a more accurate understanding of the ultrasonic testing of rock mechanical properties, which refer to UCS and Young's modulus in this paper.

\section{Experimental Materials and Testing Procedures}

2.1. Experimental Materials. The sandstone used in this research was collected from the Xin'an coal mine in Zaozhuang City, Shandong Province, China, as shown in
Figure 1. The mineral components included feldspar, quartz, kaolinite, illite, chlorite, calcite, and small amounts of other minerals. The sandstone was fine-grained with an effective porosity of $4.7 \%$. The average water content was $0.216 \%$. The average dry density was approximately $2,460 \mathrm{~kg} / \mathrm{m}^{3}$. All uniaxial tests were performed on cylindrical specimens that were $50 \mathrm{~mm}$ in diameter and $100 \mathrm{~mm}$ in length in accordance with the ISRM standard [51].

\subsection{Experimental Equipment and Testing Procedures}

2.2.1. Experimental Equipment. Conventional uniaxial compression tests were performed using an MTS815.02 Material Testing System. The maximum loading capacity was $1,700 \mathrm{kN}$. Specimens were heated using a GWD-02A electric furnace that was designed by the Ceramic Research Institute of Light Industry of China. The maximum temperature was $1,100^{\circ} \mathrm{C}$, and the variation within the furnace was $5^{\circ} \mathrm{C}$. The changes in microscopic structures were analyzed using a scanning electron microscope (SEM) on fracture surfaces in secondary electron mode. Ultrasonic testing was performed using a NM-4B nonmetal ultrasonic tester that produced ultrasonic waves with a $54-\mathrm{kHz}$ resonant frequency. The test was designed by the Beijing Koncrete Engineering Testing Technology Co., Ltd. Other equipment used in the experiment included a freeze chamber, analytical balance, and screw micrometer.

2.2.2. Testing Procedures. (1) We conducted uniaxial compression tests of sandstone after exposure to different high temperatures. The specimens were initially heated to the desired temperature $\left(400,500,600,700\right.$, or $\left.800^{\circ} \mathrm{C}\right)$ at a rate of $5^{\circ} \mathrm{C} / \mathrm{min}$. They were then held at the desired temperature for $60 \mathrm{~min}$ and subsequently cooled to room temperature $\left(20^{\circ} \mathrm{C}\right)$ in the furnace. The volume, mass, and ultrasonic Pwave velocity were measured prior to and after the hightemperature treatment. Uniaxial compression tests were then performed under displacement-controlled conditions until failure at a rate of $0.0025 \mathrm{~mm} / \mathrm{s}$ to obtain the peak strength and Young's modulus of the sandstone after exposure to the different temperatures. Young's modulus is the tangent modulus for which the axial stress is half of the peak strength in the axial stress-strain curves.

(2) We conducted uniaxial compression tests of the sandstone after F-T cycling. The samples were submerged in distilled water at $20^{\circ} \mathrm{C}$ and atmospheric pressure for $24 \mathrm{~h}$. Nondestructive tests, including volume, mass, and Pwave velocity measurements, were performed to obtain the physical parameters of the water-saturated sandstone. The saturated samples were frozen in a freeze chamber at $-20^{\circ} \mathrm{C}$ for $12 \mathrm{~h}$. They were then removed from the chamber and thawed in a deionized water bath at $+20^{\circ} \mathrm{C}$ for $12 \mathrm{~h}$. An original condition sample group was used as a control. The other five subsets were subjected to $10,20,30,40$, or 50 F-T cycles. The weight, volume, and P-wave velocity were measured again. After these nondestructive tests, uniaxial compression tests were performed to obtain the UCS and Young's modulus values. 


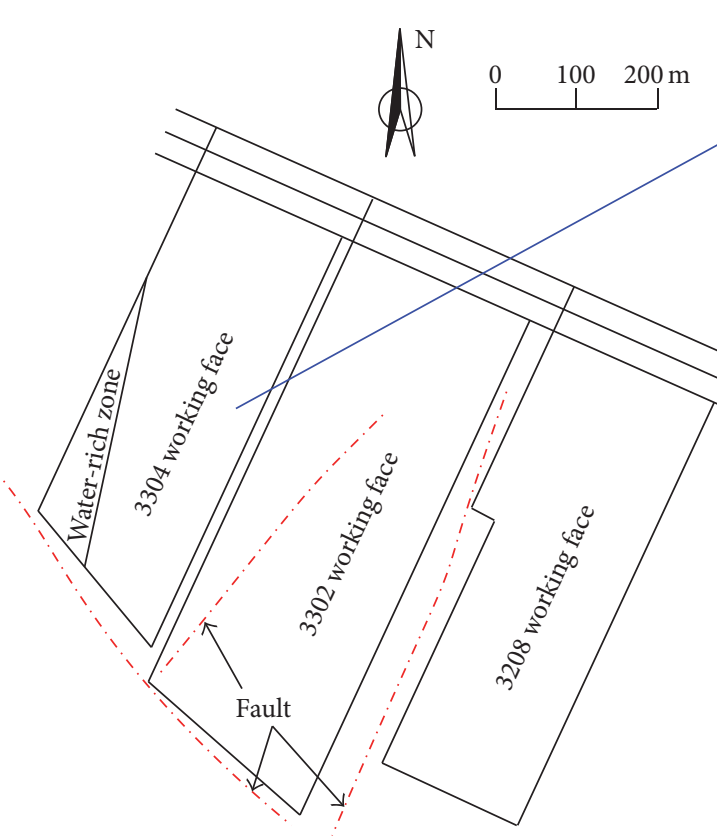

(a)

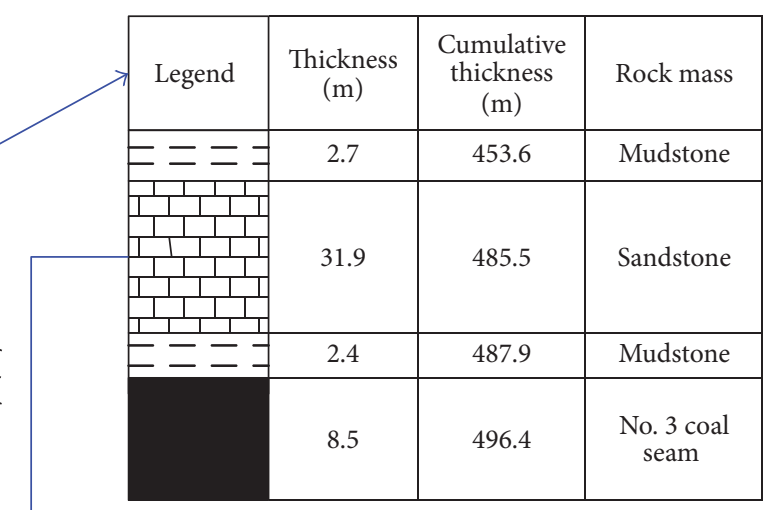

(b)

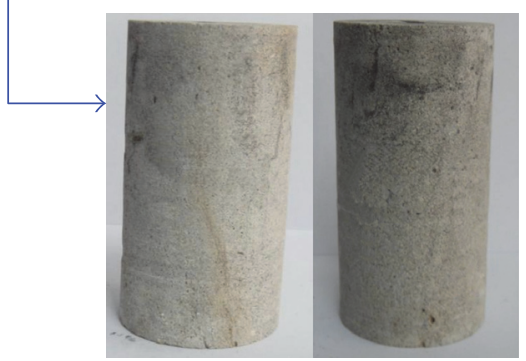

(c)

FIGURE 1: Geological conditions: (a) layout of working faces, (b) borehole column, and (c) sandstone specimens.

\section{Effect of Temperature on the Mechanical Behavior and P-Wave Velocity}

3.1. Effect of Temperature on the Physical and Mechanical Properties. High-temperature treatment significantly influences the geometry and density of the pores and cracks, thus affecting the physical and mechanical properties $[31,52]$. Table 1 illustrates the influence of temperature on the weight, volume, P-wave velocity, UCS, and Young's modulus of the sandstone.

As the temperature increased, the UCS and Young's modulus initially increased and then decreased. The maximum values occurred at $400^{\circ} \mathrm{C}$. When the temperature increased from 20 to $400^{\circ} \mathrm{C}$, the UCS increased from 62.5 to $70.9 \mathrm{MPa}$ and Young's modulus increased from 11.1 to 13.3 GPa; thus, both exhibited slight increases. When the temperature exceeded $400^{\circ} \mathrm{C}$, the high-temperature treatment significantly accelerated the evolution of damage in the sandstone. The UCS and Young's modulus at $800^{\circ} \mathrm{C}$ were 25.1 $\mathrm{MPa}$ and 2.6 GPa, respectively, which reflected decreases of $59.8 \%$ and $76.6 \%$, respectively, compared to the roomtemperature values.

Clay minerals, which are widely distributed in sandstone, are susceptible to high-temperature treatment. When the temperature was between 400 and $500^{\circ} \mathrm{C}$, the sulfide oxidation occurred in clays [53]. As the temperature continued to increase, the loss of hydroxyl groups was observed [54]. The $\partial / \beta$ transition of quartz at $573^{\circ} \mathrm{C}[6]$ also contributed to the decrease in mineral stability. Scanning electron imaging (SEM, Figure 2) was used to illustrate the microstructure changes $[55,56]$, which led to changes in the mechanical characteristics. Some original cracks were observed at room temperature. The mineral components could not freely deform during the heating process because of the constraints between the different particles; thus, the contraction and expansion of the components led to the generation of thermal stress. When the temperature was $400^{\circ} \mathrm{C}$, expansion caused the closure of pores and cracks $[55,56]$. The particle surfaces were smoother than those at room temperature, and the mechanical properties were enhanced. When the temperature was $600^{\circ} \mathrm{C}$ or above, the thermal stress reached or exceeded the tensile strength or shear strength of the sandstone components. Additionally, new cracks formed and original cracks expanded, leading to the degradation of the sandstone behavior.

The mass was measured using an analytical balance. The height and diameter were measured using a screw micrometer both before and after the heating procedure. Figure 3 illustrates the changes in the mass and volume.

The mass of the sandstone specimens sharply decreased after exposure to a temperature of $400^{\circ} \mathrm{C}$, decreasing by $0.233 \%$ compared to the room-temperature specimen, which gradually decreased. The mass at $600^{\circ} \mathrm{C}$ decreased by $0.278 \%$ compared to that at room temperature. The mass remained stable when the treatment temperature was greater than $600^{\circ} \mathrm{C}$.

When the temperature reached $400^{\circ} \mathrm{C}$, the mineral components expanded slightly and the volume increased by $0.123 \%$ compared to that at room temperature. When the temperature exceeded $400^{\circ} \mathrm{C}$, the volume of the specimens substantially increased due to the rapid increase in the thermal stress. The volume at $800^{\circ} \mathrm{C}$ increased by $2.248 \%$ compared to that at room temperature. 
TABLE 1: Characteristics of damaged specimens after high-temperature treatment.

\begin{tabular}{|c|c|c|c|c|c|c|c|c|c|c|c|}
\hline \multirow{2}{*}{ Specimen number } & \multirow{2}{*}{$\mathrm{T} /{ }^{\circ} \mathrm{C}$} & \multicolumn{2}{|c|}{$\mathrm{MCR} / \%$} & \multicolumn{2}{|c|}{$\mathrm{VCR} / \%$} & \multicolumn{2}{|c|}{$V_{\mathrm{P}} / \mathrm{m} / \mathrm{s}$} & \multicolumn{2}{|c|}{$\mathrm{UCS} / \mathrm{MPa}$} & \multicolumn{2}{|c|}{$E / G P a$} \\
\hline & & ES & AV & ES & $\mathrm{AV}$ & ES & $\mathrm{AV}$ & ES & AV & ES & $\mathrm{AV}$ \\
\hline $\mathrm{A} 1$ & 20 & - & & - & & 4193 & & 60.2 & & 11.0 & \\
\hline $\mathrm{A} 2$ & 20 & - & & - & & 4083 & & 62.7 & & 10.1 & \\
\hline A3 & 20 & - & - & - & - & 4286 & 4262 & 65.8 & 62.5 & 12.0 & 11.1 \\
\hline A4 & 20 & - & & - & & 4487 & & 61.4 & & 11.4 & \\
\hline B1 & 400 & -0.214 & & 0.134 & & 4593 & & 71.4 & & 13.5 & \\
\hline B2 & 400 & -0.229 & & 0.113 & & 4462 & & 73.8 & & 14.2 & \\
\hline B3 & 400 & -0.236 & -0.233 & 0.127 & 0.123 & 4451 & 4468 & 69.4 & 70.9 & 12.6 & 13.3 \\
\hline B4 & 400 & -0.251 & & 0.118 & & 4367 & & 68.9 & & 12.8 & \\
\hline $\mathrm{C} 1$ & 500 & -0.231 & & 0.337 & & 4068 & & 65.4 & & 10.8 & \\
\hline $\mathrm{C} 2$ & 500 & -0.246 & & 0.331 & & 3956 & & 62.8 & & 9.2 & \\
\hline $\mathrm{C} 3$ & 500 & -0.253 & -0.247 & 0.351 & 0.334 & 3873 & 3952 & 59.7 & 63.3 & 8.9 & 10.0 \\
\hline $\mathrm{C} 4$ & 500 & -0.259 & & 0.316 & & 3912 & & 65.1 & & 10.9 & \\
\hline D1 & 600 & -0.286 & & 0.798 & & 3700 & & 50.2 & & 6.7 & \\
\hline D2 & 600 & -0.279 & & 0.847 & & 3386 & & 48.6 & & 6.1 & \\
\hline D3 & 600 & -0.281 & -0.278 & 0.812 & 0.808 & 3761 & 3515 & 51.4 & 51.2 & 6.9 & 6.6 \\
\hline D4 & 600 & -0.267 & & 0.776 & & 3214 & & 54.6 & & 6.8 & \\
\hline E1 & 700 & -0.298 & & 1.357 & & 3567 & & 39.6 & & 4.8 & \\
\hline E2 & 700 & -0.287 & & 1.376 & & 3200 & & 41.6 & & 4.3 & \\
\hline E3 & 700 & -0.292 & -0.289 & 1.314 & 1.336 & 3461 & 3339 & 42.9 & 40.4 & 5.6 & 4.6 \\
\hline E4 & 700 & -0.279 & & 1.296 & & 3128 & & 37.6 & & 3.7 & \\
\hline $\mathrm{F} 1$ & 800 & -0.301 & & 2.272 & & 2721 & & 27.2 & & 3.1 & \\
\hline F2 & 800 & -0.293 & & 2.314 & & 2613 & & 24.4 & & 2.4 & \\
\hline F3 & 800 & -0.296 & -0.293 & 2.183 & 2.248 & 2704 & 2644 & 25.3 & 25.1 & 2.6 & 2.6 \\
\hline F4 & 800 & -0.283 & & 2.223 & & 2539 & & 23.5 & & 2.1 & \\
\hline
\end{tabular}

Note: $T$ is the temperature, MCR is the mass change rate, VCR is the volume change rate, $V_{\mathrm{P}}$ is the P-wave velocity, UCS is the uniaxial compressive strength, $E$ is Young's modulus, ES is each specimen, and AV is the average value.

3.2. Relationship between the P-Wave Velocity and Mechanical Properties. The P-wave velocity initially increased and then decreased. When the temperature increased from room temperature to $400^{\circ} \mathrm{C}$, the $\mathrm{P}$-wave velocity increased to $4,468 \mathrm{~m} / \mathrm{s}$ - an increase of $4.8 \%$ compared to $4,262 \mathrm{~m} / \mathrm{s}$ at room temperature. When the temperature reached $800^{\circ} \mathrm{C}$, the $\mathrm{P}$-wave velocity decreased to $2,644 \mathrm{~m} / \mathrm{s}$ - a decrease of $38.0 \%$. This change was due to water evaporation from the pores and an increase in the crack volume. Moreover, new cracks formed and the original cracks expanded because of the different thermal expansion rates of the mineral components. A relationship was observed between the UCS, Young's modulus, and P-wave velocity. In general, the UCS and Young's modulus increased as the P-wave velocity increased; however, there were many exceptions to this trend, as shown in Figures 4 and 5. The data in box S1 of Figure 4 indicate that the UCS values of different specimens are remarkably different, whereas the P-wave velocities are approximately the same. The data in box S2 of Figure 4 indicate that the Pwave velocities are significantly different, whereas the UCS values are approximately the same. The data in box S3 of Figure 4 indicate that UCS may be negatively correlated with the P-wave velocity. Similar experimental results are observed between the P-wave velocity and Young's modulus, as shown in boxes S4, S5, and S6 of Figure 5.

\section{Effect of F-T Cycling on the Mechanical Behavior and P-Wave Velocity}

4.1. Effect of F-T Cycling on the Mechanical Behavior. The freezing of water leads to a volume increase of approximately $9 \%$ [41], which generates pressure on the walls of pores and cracks. When the ice crystallization pressure reaches the tension strength of the rock, new microfractures develop and existing cracks widen. When the rock thaws, water flows through other pores and cracks and further weakens the material $[57,58]$. Table 2 presents the characteristics of the damaged sandstone after different F-T cycles.

Figure 6 illustrates that, in the initial $30 \mathrm{~F}-\mathrm{T}$ cycles, the mass and volume increased by $0.63 \%$ and $0.53 \%$, respectively, compared to the values measured before F-T cycling. This volume increase was a result of water freezing, which caused both the water and cracks to expand. The mass increase resulted from the external water flowing into the newly formed cracks.

Figures 7 and 8 illustrate the change in the UCS and Young's modulus. The mechanical characteristics deteriorated as the number of F-T cycles increased. In the initial 30 cycles, both UCS and Young's modulus decreased sharply. The UCS decreased from 62.9 MPa before F-T cycling to 44.8, 33.8 , and $26.1 \mathrm{MPa}$ after 10,20 , and 30 cycles, respectively, 


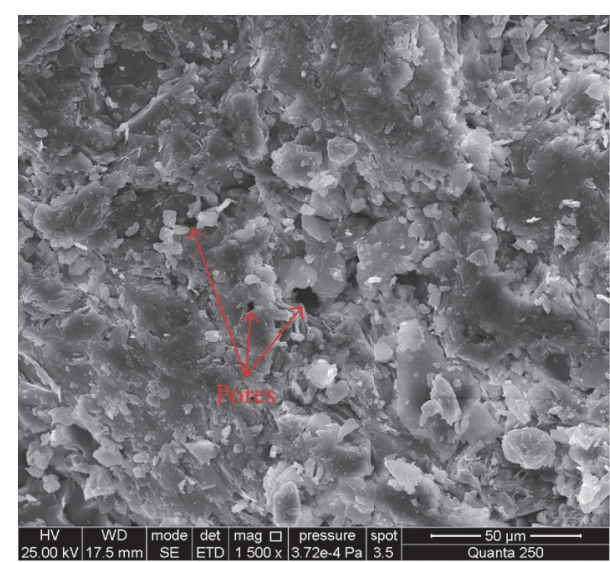

(a) $20^{\circ} \mathrm{C}$

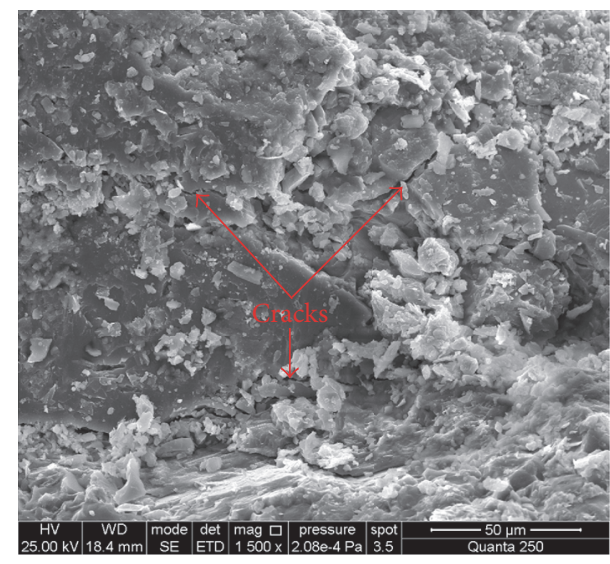

(c) $600^{\circ} \mathrm{C}$

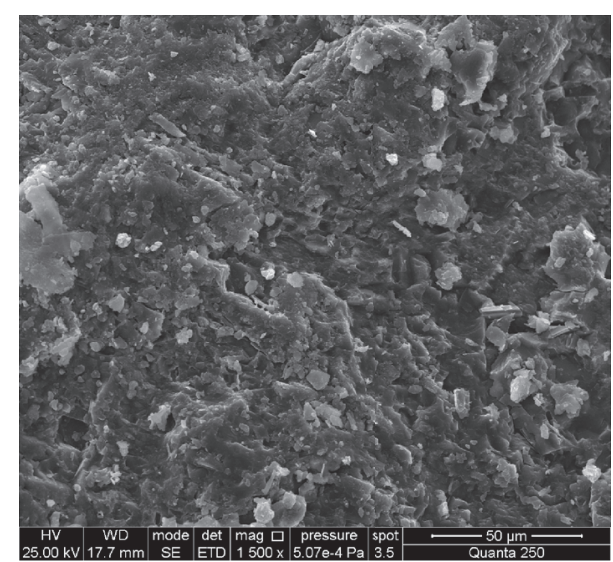

(b) $400^{\circ} \mathrm{C}$

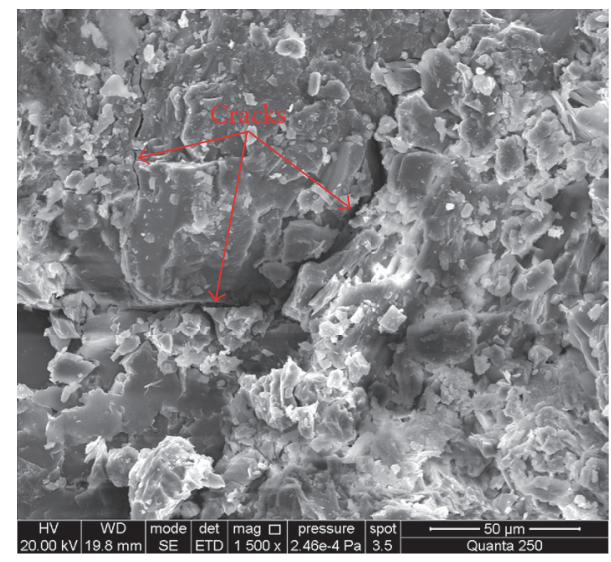

(d) $800^{\circ} \mathrm{C}$

FIGURE 2: SEM observations of sandstone after different high-temperature treatments.

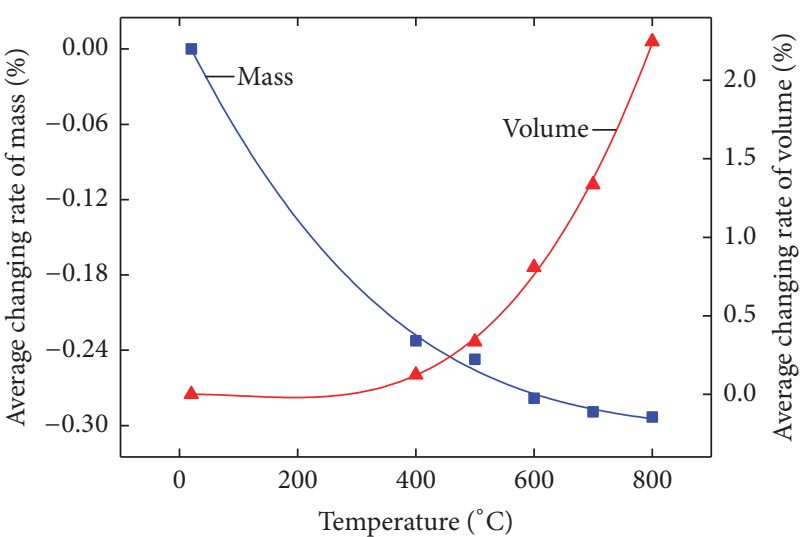

FIGURE 3: Effect of high-temperature treatment on the mass and volume of sandstone specimens.

reflecting decreases of $28.8 \%, 46.3 \%$, and $58.5 \%$. Young's modulus values decreased from $11.8 \mathrm{GPa}$ to $8.6,6.6$, and $5.0 \mathrm{GPa}$ after 10,20 , and 30 cycles, respectively, reflecting decreases of $27.1 \%, 44.1 \%$, and $57.6 \%$. The mechanical properties further deteriorated after 40 and 50 cycles, but the rates were not significant. The UCS values after 40 and 50 cycles were 21.6 and $17.3 \mathrm{MPa}$, respectively, which reflected decreases of $65.7 \%$ and $72.5 \%$ compared to the values before F-T cycling. Additionally, Young's modulus values were 4.3 and $3.2 \mathrm{GPa}$, which reflected decreases of $63.6 \%$ and $72.9 \%$, respectively. The changes in mechanical properties indicated that deterioration primarily occurred during earlier F-T cycles and was less significant in the latter cycles.

4.2. Effect of F-T Cycling on the P-Wave Velocity. The formation of new cracks and the expansion of existing cracks resulted in a decrease in the $\mathrm{P}$-wave velocity, and this trend was different from that of the mechanical properties during F-T cycling. Figure 9 illustrates that the P-wave velocity decreased from $4,085 \mathrm{~m} / \mathrm{s}$ before F-T cycling to 3,470 and $3,032 \mathrm{~m} / \mathrm{s}$ after 10 and 20 cycles, respectively, reflecting decreases of $15.1 \%$ and $25.8 \%$. However, in latter cycles, trend exhibited a slight increase followed by a decrease. After 30, 40 , and 50 cycles, the P-wave velocities were 2,945, 3,055, and $3,026 \mathrm{~m} / \mathrm{s}$, respectively, and the associated decreases were $27.9 \%, 25.2 \%$, and $25.9 \%$, respectively, compared to the values before F-T cycling. 
TABLE 2: Characteristics of damaged specimens after different numbers of F-T cycles.

\begin{tabular}{|c|c|c|c|c|c|c|c|c|c|c|c|}
\hline \multirow{2}{*}{ Specimen number } & \multirow{2}{*}{ F-T Cycles } & \multicolumn{2}{|c|}{$\mathrm{MCR} / \%$} & \multicolumn{2}{|c|}{$\mathrm{VCR} / \%$} & \multicolumn{2}{|c|}{$V_{\mathrm{P}} / \mathrm{m} / \mathrm{s}$} & \multicolumn{2}{|c|}{$\mathrm{UCS} / \mathrm{MPa}$} & \multicolumn{2}{|c|}{$E / G P a$} \\
\hline & & ES & $\mathrm{AV}$ & ES & AV & ES & AV & ES & $\mathrm{AV}$ & ES & AV \\
\hline G1 & 0 & - & - & - & - & 4092 & & 64.2 & & 12.0 & \\
\hline G2 & 0 & - & - & - & - & 3987 & & 59.6 & & 11.2 & \\
\hline G3 & 0 & - & - & - & - & 4068 & 4085 & 62.7 & 62.9 & 11.5 & 11.8 \\
\hline G4 & 0 & - & - & - & - & 4190 & & 65.0 & & 12.6 & \\
\hline $\mathrm{H} 1$ & 10 & 0.46 & & 0.34 & & 3512 & & 47.5 & & 9.2 & \\
\hline $\mathrm{H} 2$ & 10 & 0.43 & & 0.25 & & 3363 & & 42.6 & & 8.6 & \\
\hline $\mathrm{H} 3$ & 10 & 0.31 & 0.42 & 0.32 & 0.32 & 3527 & 3470 & 43.1 & 44.8 & 7.9 & 8.6 \\
\hline $\mathrm{H} 4$ & 10 & 0.47 & & 0.37 & & 3476 & & 45.8 & & 8.8 & \\
\hline I1 & 20 & 0.51 & & 0.55 & & 3002 & & 32.3 & & 6.8 & \\
\hline $\mathrm{I} 2$ & 20 & 0.56 & & 0.36 & & 3127 & & 37.8 & & 7.2 & \\
\hline I3 & 20 & 0.46 & 0.54 & 0.50 & 0.45 & 3014 & 3032 & 35.6 & 33.8 & 6.6 & 6.6 \\
\hline I4 & 20 & 0.63 & & 0.37 & & 2983 & & 29.6 & & 5.9 & \\
\hline J1 & 30 & 0.72 & & 0.49 & & 3097 & & 26.8 & & 5.1 & \\
\hline $\mathrm{J} 2$ & 30 & 0.53 & & 0.58 & & 2822 & & 21.9 & & 4.4 & \\
\hline $\mathrm{J} 3$ & 30 & 0.68 & 0.63 & 0.46 & 0.53 & 2982 & 2945 & 28.0 & 26.1 & 5.8 & 5.0 \\
\hline $\mathrm{J} 4$ & 30 & 0.60 & & 0.60 & & 2879 & & 27.7 & & 4.6 & \\
\hline $\mathrm{K} 1$ & 40 & 0.57 & & 0.46 & & 2910 & & 22.0 & & 4.1 & \\
\hline $\mathrm{K} 2$ & 40 & 0.64 & & 0.53 & & 3242 & & 21.7 & & 4.1 & \\
\hline K3 & 40 & 0.59 & 0.63 & 0.49 & 0.52 & 2954 & 3055 & 17.3 & 21.6 & 4.3 & 4.3 \\
\hline K4 & 40 & 0.71 & & 0.58 & & 3114 & & 25.5 & & 4.6 & \\
\hline L1 & 50 & 0.53 & & 0.43 & & 2973 & & 19.2 & & 2.9 & \\
\hline L2 & 50 & 0.69 & & 0.50 & & 2876 & & 15.8 & & 2.7 & \\
\hline L3 & 50 & 0.48 & 0.58 & 0.55 & 0.48 & 3078 & 3026 & 17.1 & 17.3 & 3.4 & 3.2 \\
\hline $\mathrm{L} 4$ & 50 & 0.62 & & 0.44 & & 3176 & & 16.9 & & 3.6 & \\
\hline
\end{tabular}

Note: MCR is the mass change rate, VCR is the volume change rate, $V_{\mathrm{P}}$ is the P-wave velocity, UCS is the uniaxial compressive strength, $E$ is Young's modulus, $\mathrm{ES}$ is each specimen, and AV is the average value.

\section{Discussion of the Relationship between the P-Wave Velocity and the Mechanical Properties of Damaged Rock}

In the latter F-T cycles, the amount of water in the pores and cracks decreased based on mass variations. However, deterioration primarily occurred in earlier cycles. The formation of new cracks and the expansion of existing cracks slowed in the latter cycles. During this period, the crack space accommodated the expanding volume of the freezing water. The freeze-thaw damage was mainly due to the hydraulic pressures that formed during freezing and thawing [41, 57]. The formation of new cracks and the expansion of existing cracks required pressure, which was provided by the ice crystallization pressure in earlier cycles and by the different expansion rates of the mineral components in the latter cycles. The pressures in the latter cycles were significantly lower than those in earlier cycles.

We performed uniaxial compression tests after different high-temperature treatments and F-T cycles. Our results showed a generally positive relationship between the P-wave velocity and mechanical characteristics, although there were many exceptions. The UCS, Young's modulus, and P-wave velocity exhibited different macrobehaviors in the specimens. UCS represents the carrying capacity of the weak plane and is

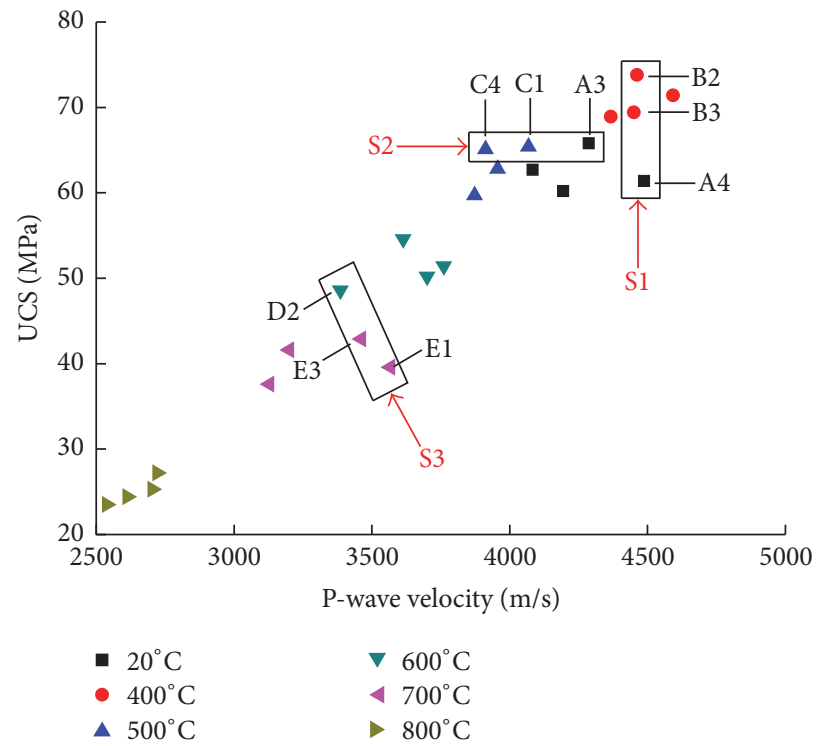

FIGURE 4: Relationship between the P-wave velocity and UCS.

closely related to the stress state. Young's modulus represents the correlation between the local deformation and applied 


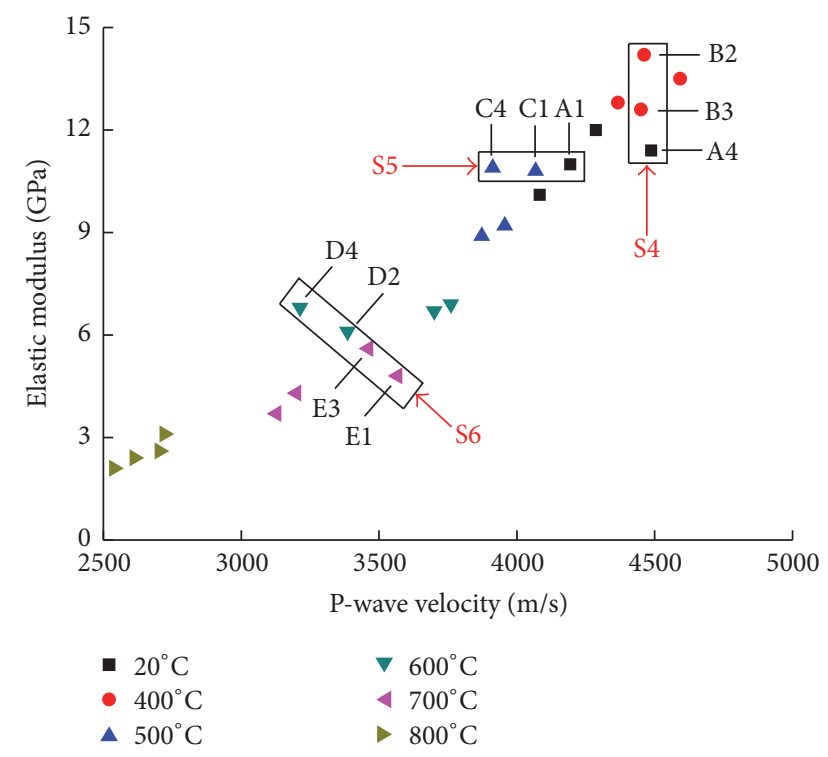

Figure 5: Relationship between the P-wave velocity and Young's modulus.

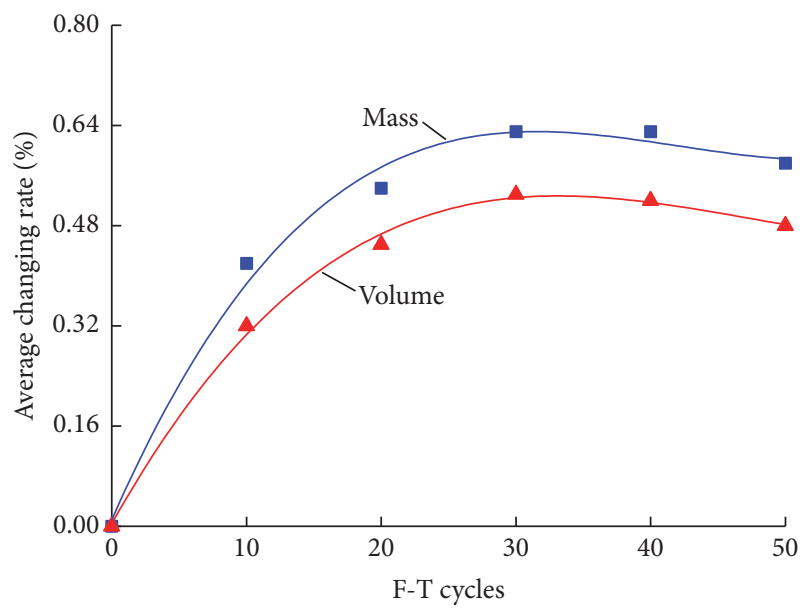

FIGURE 6: Effects of F-T cycling on the mass and volume of the sandstone specimens.

stress, which is influenced by the loading path. The P-wave velocity in a free condition is a general reflection of the rock deformation characteristics and fracture state. P-wave velocity is separately used in many ultrasonic measurements that do not provide useful information such as the acoustic frequency, maximum amplitude of the frequency domain, and area of the frequency spectrum. P-wave velocity cannot represent the acoustic characteristics of rock comprehensively, as the prediction accuracy is low and errors are often observed. We conjecture that open cracks, which are perpendicular to the axial direction, cause significant deterioration of the P-wave velocity. However, they have an insignificant effect on the UCS. Closed cracks, which have a $60^{\circ}$ angle with the axial direction, decrease the UCS, even though the Pwave velocity remains stable, as shown in Figure 10. Different high-temperature treatments and F-T cycles cause different

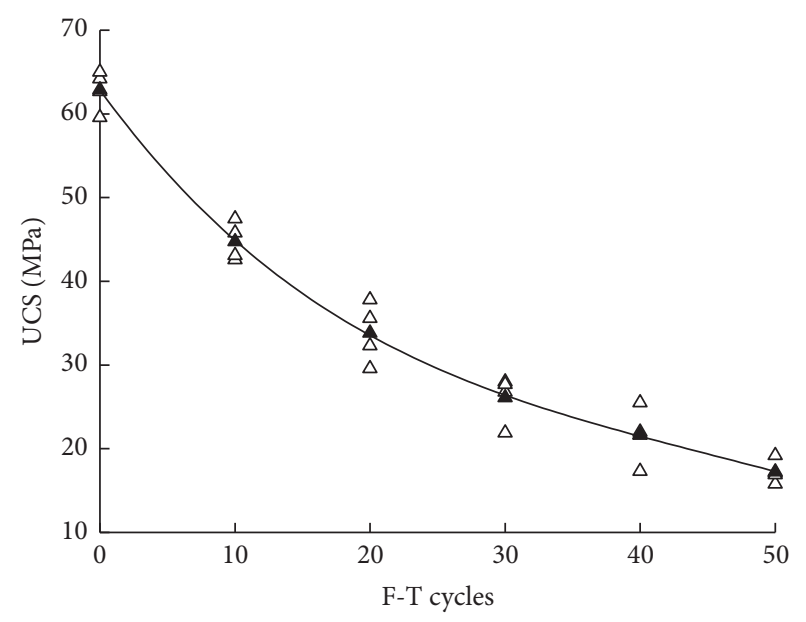

$\triangle$ Each specimen

\ Average value

FIGURE 7: UCS variations after F-T cycling.

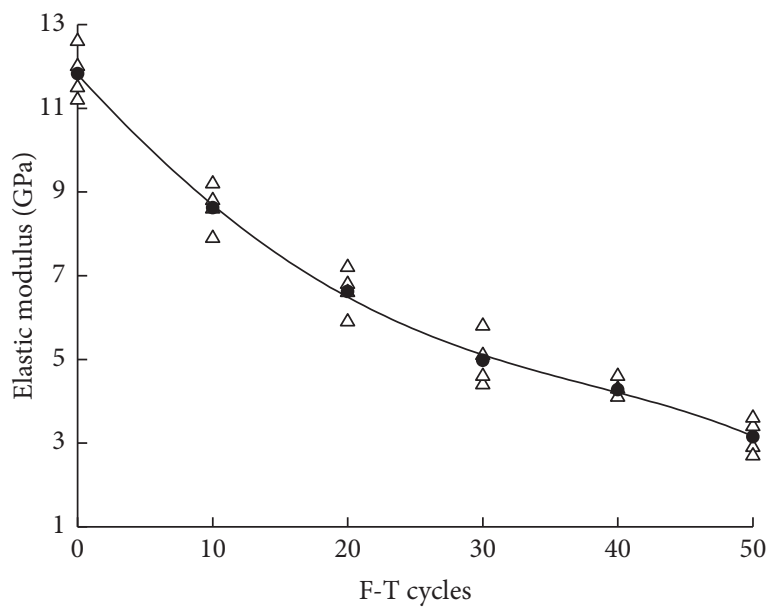

$\triangle$ Each specimen

- Average value

FIGURE 8: Young's modulus variations after F-T cycling.

degrees of deterioration. Our experimental results showed that UCS may significantly increase, whereas the P-wave velocity decreases sharply. The former occurred because the contact condition of particles in the weak plane increased. The latter resulted from the degradation of stiffness, which was caused by general damage to mineral components [59, $60]$.

In future research, we plan to transfer the time domain signal to a frequency domain signal using Fast Fourier Transform (FFT) and use wavelet analysis to study the digital signal. Thus, it is essential to understand ultrasonic measurements from comprehensive perspectives, such as the velocity, amplitude, and waveform perspectives. 


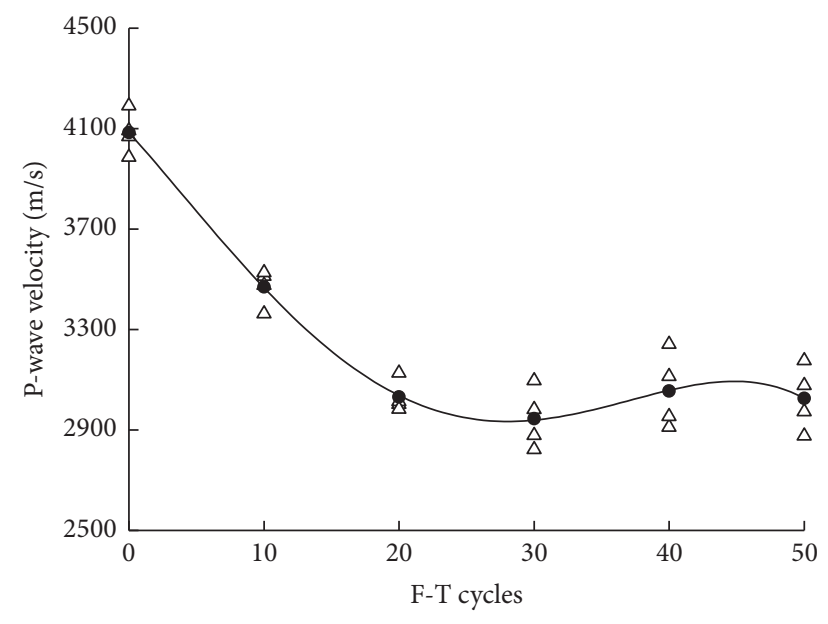

$\triangle$ Each specimen

- Average value

FIGURE 9: P-wave velocity variations after F-T cycling.

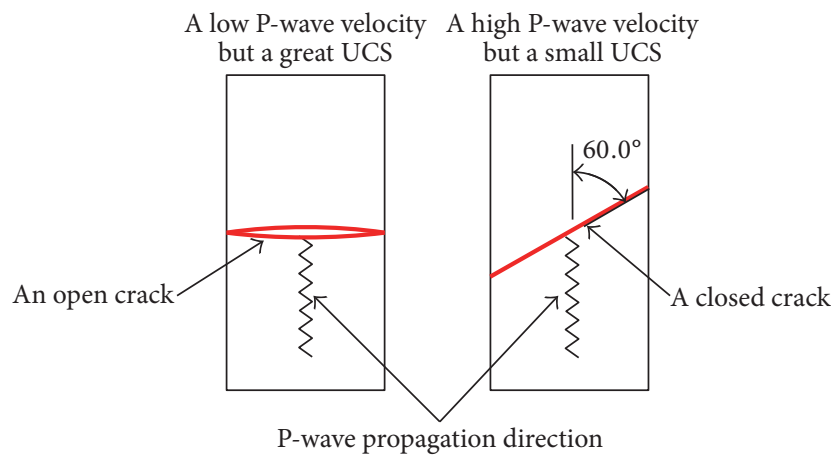

FIGURE 10: Unrelated correlation between the P-wave velocity and UCS.

\section{Conclusions}

Uniaxial compression tests under high-temperature treatments and F-T cycling were performed to understand the relationship between the P-wave velocity and the mechanical properties of damaged sandstone. The following conclusions can be drawn from this study:

(1) Exposure to high temperature contributes to more textural flaws in sandstone. When the temperature increased from room temperature to $400^{\circ} \mathrm{C}$, the mechanical properties exhibited a slight enhancement. Scanning electron microscopy images indicated that when the temperature exceeded $400^{\circ} \mathrm{C}$, new cracks formed, the original cracks expanded, and the volume of the specimen rapidly increased. As the treatment temperature increased, the UCS and Young's modulus sharply decreased. The UCS and Young's modulus at $800^{\circ} \mathrm{C}$ were $25.1 \mathrm{MPa}$ and $2.6 \mathrm{GPa}$, respectively, which reflected decreases of $59.8 \%$ and $76.6 \%$, respectively, compared to the room-temperature values. In general, the $\mathrm{P}$ wave velocity increased when the UCS and Young's modulus increased. However, there were many exceptions. Our experimental data indicated that the mechanical properties displayed significant differences for a given P-wave velocity. When the P-wave velocity increases, the UCS and Young's modulus may significantly decrease or exhibit an insignificant change.

(2) The mechanical behavior deteriorated as the number of F-T cycles increased. In the initial 30 cycles, the mechanical characteristics sharply decreased. After 10, 20, and 30 cycles, the UCS decreased by $28.8 \%, 46.3 \%$, and $58.5 \%$, respectively, compared to the values before F-T cycling. Young's modulus values decreased by $27.1 \%, 44.1 \%$, and $57.6 \%$ after 10,20 , and 30 cycles, respectively. After 40 and 50 cycles, the mechanical properties deteriorated further but only slightly. The P-wave velocity trend differed from mechanical property trends during F-T cycling. The P-wave velocity decreased sharply in the initial 20 cycles. After 10 and 20 cycles, the P-wave velocity decreased by $15.1 \%$ and $25.8 \%$, respectively, compared to that before F-T cycling. However, after 30, 40, and 50 cycles, the trend slightly increased before decreasing again.

(3) The UCS, Young's modulus, and P-wave velocity represent different macrobehaviors of rock properties. There is a statistical relationship between the P-wave velocity and mechanical properties, such as the UCS and Young's modulus, but there is no mechanical relationship. Further attention is warranted when using ultrasonic testing to predict mechanical characteristics.

\section{Competing Interests}

The authors declare that they have no competing interests.

\section{Acknowledgments}

This study was supported by the National Basic Research Program of China (Grant no. 2013CB227900) and the National Natural Science Foundation of China (Grants nos. 51304206 and 51421003).

\section{References}

[1] B. Garitte, A. Gens, J. Vaunat, and G. Armand, "Thermal conductivity of argillaceous rocks: determination methodology using in situ heating tests," Rock Mechanics and Rock Engineering, vol. 47, no. 1, pp. 111-129, 2014.

[2] J. Luo and L. G. Wang, "High-temperature mechanical properties of mudstone in the process of underground coal gasification," Rock Mechanics and Rock Engineering, vol. 44, no. 6, pp. 749-754, 2011.

[3] M. Najafi, S. M. E. Jalali, and R. KhaloKakaie, "Thermalmechanical-numerical analysis of stress distribution in the vicinity of underground coal gasification (UCG) panels," International Journal of Coal Geology, vol. 134-135, pp. 1-16, 2014.

[4] F. E. Heuze, "High-temperature mechanical, physical and thermal properties of granitic rocks-a review," International Journal of Rock Mechanics and Mining Sciences \& Geomechanics Abstracts, vol. 20, no. 1, pp. 3-10, 1983.

[5] Y. Géraud, F. Mazerolle, and S. Raynaud, "Comparison between connected and overall porosity of thermally stressed granites," Journal of Structural Geology, vol. 14, no. 8-9, pp. 981-990, 1992. 
[6] P. W. J. Glover, P. Baud, M. Darot et al., " $\alpha / \beta$ phase transition in quartz monitored using acoustic emissions," Geophysical Journal International, vol. 120, no. 3, pp. 775-782, 1995.

[7] P. N. Chopra, "High-temperature transient creep in olivine rocks," Tectonophysics, vol. 279, no. 1-4, pp. 93-111, 1997.

[8] Y. Zhao, Z. Wan, Z. Feng, D. Yang, Y. Zhang, and F. Qu, “Triaxial compression system for rock testing under high temperature and high pressure," International Journal of Rock Mechanics and Mining Sciences, vol. 52, pp. 132-138, 2012.

[9] A. Ozguven and Y. Ozcelik, "Effects of high temperature on physico-mechanical properties of Turkish natural building stones," Engineering Geology, vol. 183, pp. 127-136, 2014.

[10] L. Zhang, X. Mao, R. Liu, X. Guo, and D. Ma, "The mechanical properties of mudstone at high temperatures: An Experimental Study," Rock Mechanics and Rock Engineering, vol. 47, no. 4, pp. 1479-1484, 2014.

[11] Z. Z. Zhang, X. L. Xu, Q. P. Sun, and Y. Dong, "Effect of thermal treatment on fractals in acoustic emission of rock material," Advances in Materials Science and Engineering, vol. 2016, Article ID 6309856, 9 pages, 2016.

[12] A. M. Ferrero and P. Marini, "Experimental studies on the mechanical behaviour of two thermal cracked marbles," Rock Mechanics and Rock Engineering, vol. 34, no. 1, pp. 57-66, 2001.

[13] W. G. Liang, S. G. Xu, and Y. S. Zhao, "Experimental study of temperature effects on physical and mechanical characteristics of salt rock," Rock Mechanics and Rock Engineering, vol. 39, no. 5, pp. 469-482, 2006.

[14] V. Brotóns, R. Tomás, S. Ivorra, and J. C. Alarcón, “Temperature influence on the physical and mechanical properties of a porous rock: San Julian's calcarenite," Engineering Geology, vol. 167, pp. 117-127, 2013.

[15] N. Sengun, "Influence of thermal damage on the physical and mechanical properties of carbonate rocks," Arabian Journal of Geosciences, vol. 7, no. 12, pp. 5543-5551, 2014.

[16] Y. Ozcelik, N. Careddu, and E. Yilmazkaya, "The effects of freeze-thaw cycles on the gloss values of polished stone surfaces," Cold Regions Science and Technology, vol. 82, pp. 49-55, 2012.

[17] M. S. Baghini and A. Ismail, "Freeze-thaw performance and moisture-induced damage resistance of base course stabilized with slow setting bitumen emulsion-Portland cement additives," Advances in Materials Science and Engineering, vol. 2015, Article ID 348691, 10 pages, 2015.

[18] C. Karakurt and Y. Bayazit, "Freeze-thaw resistance of normal and high strength concretes produced with fly ash and silica fume," Advances in Materials Science and Engineering, vol. 2015, Article ID 830984, 2015.

[19] A. C. Iñigo, M. A. Vicente, and V. Rives, "Weathering and decay of granitic rocks: its relation to their pore network," Mechanics of Materials, vol. 32, no. 9, pp. 555-560, 2000.

[20] T. C. Chen, M. R. Yeung, and N. Mori, "Effect of water saturation on deterioration of welded tuff due to freeze-thaw action," Cold Regions Science and Technology, vol. 38, no. 2-3, pp. 127-136, 2004.

[21] M. Hori and H. Morihiro, "Micromechanical analysis on deterioratIon due to freezing and thawing in porous brittle materials," International Journal of Engineering Science, vol. 36, no. 4, pp. 511-522, 1998.

[22] X. Tan, W. Chen, J. Yang, and J. Cao, "Laboratory investigations on the mechanical properties degradation of granite under freeze-thaw cycles," Cold Regions Science and Technology, vol. 68, no. 3, pp. 130-138, 2011.
[23] S. Siegesmund, K. Ullemeyer, T. Weiss, and E. K. Tschegg, "Physical weathering of marbles caused by anisotropic thermal expansion," International Journal of Earth Sciences, vol. 89, no. 1, pp. 170-182, 2000.

[24] H. Yavuz, R. Altindag, S. Sarac, I. Ugur, and N. Sengun, "Estimating the index properties of deteriorated carbonate rocks due to freeze-thaw and thermal shock weathering," International Journal of Rock Mechanics and Mining Sciences, vol. 43, no. 5, pp. 767-775, 2006.

[25] M. Takarli, W. Prince, and R. Siddique, "Damage in granite under heating/cooling cycles and water freeze-thaw condition," International Journal of Rock Mechanics and Mining Sciences, vol. 45, no. 7, pp. 1164-1175, 2008.

[26] Z. Karaca, A. Hamdi Deliormanli, H. Elci, and C. Pamukcu, "Effect of freeze-thaw process on the abrasion loss value of stones," International Journal of Rock Mechanics and Mining Sciences, vol. 47, no. 7, pp. 1207-1211, 2010.

[27] A. Saad, S. Guédon, and F. Martineau, "Microstructural weathering of sedimentary rocks by freeze-thaw cycles: experimental study of state and transfer parameters," Comptes RendusGeoscience, vol. 342, no. 3, pp. 197-203, 2010.

[28] F. Bayram, "Predicting mechanical strength loss of natural stones after freeze-thaw in cold regions," Cold Regions Science and Technology, vol. 83-84, pp. 98-102, 2012.

[29] A. C. Iñigo, J. García-Talegón, S. Vicente-Tavera et al., “Colour and ultrasound propagation speed changes by different ageing of freezing/thawing and cooling/heating in granitic materials," Cold Regions Science and Technology, vol. 85, pp. 71-78, 2013.

[30] C. Moreno De Jong Van Coevorden, C. Cobos Sánchez, A. Rubio Bretones, M. Fernández Pantoja, S. G. Garca, and R. Gómez Martn, "Nondestructive evaluation of the preservation state of stone columns in the Hospital Real of Granada," Nondestructive Testing and Evaluation, vol. 27, no. 4, pp. 335351, 2012.

[31] M. Darot and T. Reuschlé, "Acoustic wave velocity and permeability evolution during pressure cycles on a thermally cracked granite," International Journal of Rock Mechanics and Mining Sciences, vol. 37, no. 7, pp. 1019-1026, 2000.

[32] K. Malaga-Starzec, U. Åkesson, J. E. Lindqvist, and B. Schouenborg, "Microscopic and macroscopic characterization of the porosity of marble as a function of temperature and impregnation," Construction and Building Materials, vol. 20, no. 10, pp. 939-947, 2006

[33] J. Ruedrich and S. Siegesmund, "Salt and ice crystallisation in porous sandstones," Environmental Geology, vol. 52, no. 2, pp. 343-367, 2007.

[34] A. B. Yavuz and T. Topal, “Thermal and salt crystallization effects on marble deterioration: examples from Western Anatolia, Turkey," Engineering Geology, vol. 90, no. 1-2, pp. 30-40, 2007.

[35] J. Ruedrich, D. Kirchner, and S. Siegesmund, "Physical weathering of building stones induced by freeze-thaw action: a laboratory long-term study," Environmental Earth Sciences, vol. 63, no. 7, pp. 1573-1586, 2011.

[36] J.-S. Lee and H.-K. Yoon, "Theoretical relationship between elastic wave velocity and electrical resistivity," Journal of Applied Geophysics, vol. 116, pp. 51-61, 2015.

[37] J. Ma, G. Zhao, L. Dong, G. Chen, and C. Zhang, "A comparison of mine seismic discriminators based on features of source parameters to waveform characteristics," Shock and Vibration, vol. 2015, Article ID 919143, 2015. 
[38] N. Jiang, C. Zhou, X. Luo, and S. Lu, "Damage characteristics of surrounding rock subjected to VCR mining blasting shock," Shock and Vibration, vol. 2015, Article ID 373021, 8 pages, 2015.

[39] J. Martínez-Martínez, D. Benavente, and M. A. García-delCura, "Spatial attenuation: the most sensitive ultrasonic parameter for detecting petrographic features and decay processes in carbonate rocks," Engineering Geology, vol. 119, no. 3-4, pp. 8495, 2011.

[40] G. Concu, B. De Nicolo, and M. Valdes, "Prediction of building limestone physical and mechanical properties by means of ultrasonic P-wave velocity," The Scientific World Journal, vol. 2014, Article ID 508073, 8 pages, 2014.

[41] H. Yavuz, "Effect of freeze-thaw and thermal shock weathering on the physical and mechanical properties of an andesite stone," Bulletin of Engineering Geology and the Environment, vol. 70, no. 2, pp. 187-192, 2011.

[42] J.-S. Lee and H.-K. Yoon, "Porosity estimation based on seismic wave velocity at shallow depths," Journal of Applied Geophysics, vol. 105, pp. 185-190, 2014.

[43] A. Aquino-López, A. Mousatov, M. Markov, and E. Kazatchenko, "Modeling and inversion of elastic wave velocities and electrical conductivity in clastic formations with structural and dispersed shales," Journal of Applied Geophysics, vol. 116, pp. 28-42, 2015.

[44] Z. Song, J. Wang, A. Jiang, X. Liu, and X. Zhang, "Ultrasonic tests on schist with saturated fractures under uniaxial compression," Chinese Journal of Rock Mechanics and Engineering, vol. 33, no. 12, pp. 2377-2383, 2014.

[45] Z. Lafhaj, M. Goueygou, A. Djerbi, and M. Kaczmarek, "Correlation between porosity, permeability and ultrasonic parameters of mortar with variable water/cement ratio and water content," Cement and Concrete Research, vol. 36, no. 4, pp. 625-633, 2006.

[46] M. Goueygou, Z. Lafhaj, and F. Soltani, "Assessment of porosity of mortar using ultrasonic Rayleigh waves," NDT and E International, vol. 42, no. 5, pp. 353-360, 2009.

[47] J.-H. Byun, J.-S. Lee, K. Park, and H.-K. Yoon, "Prediction of crack density in porous-cracked rocks from elastic wave velocities," Journal of Applied Geophysics, vol. 115, pp. 110-119, 2015.

[48] M. G. Hernández, M. A. G. Izquierdo, A. Ibáñez, J. J. Anaya, and L. G. Ullate, "Porosity estimation of concrete by ultrasonic NDE,” Ultrasonics, vol. 38, no. 1, pp. 531-533, 2000.

[49] S. Assefa, C. McCann, and J. Sothcott, "Velocities of compressional and shear waves in limestones," Geophysical Prospecting, vol. 51, no. 1, pp. 1-13, 2003.

[50] W. Punurai, J. Jarzynski, J. Qu, K. E. Kurtis, and L. J. Jacobs, "Characterization of entrained air voids in cement paste with scattered ultrasound," NDT and E International, vol. 39, no. 6 , pp. 514-524, 2006.

[51] C. E. Fairhurst and J. A. Hudson, "Draft ISRM suggested method for the complete stressstrain curve for the intact rock in uniaxial compression," International Journal of Rock Mechanics and Mining Sciences, vol. 36, no. 3, pp. 279-289, 1999.

[52] H. Yavuz, S. Demirdag, and S. Caran, "Thermal effect on the physical properties of carbonate rocks," International Journal of Rock Mechanics and Mining Sciences, vol. 47, no. 1, pp. 94-103, 2010.

[53] S. McCabe, B. J. Smith, and P. A. Warke, "Exploitation of inherited weakness in fire-damaged building sandstone: the 'fatiguing' of 'shocked' stone," Engineering Geology, vol. 115, no. 3-4, pp. 217-225, 2010.
[54] Q. Sun, Z. Zhang, L. Xue, and S. Zhu, "Physico-mechanical properties variation of rock with phase transformation under high temperature," Chinese Journal of Rock Mechanics and Engineering, vol. 32, no. 5, pp. 935-942, 2013.

[55] Q.-L. Ding, F. Ju, X.-B. Mao, D. Ma, B.-Y. Yu, and S.-B. Song, "Experimental investigation of the mechanical behavior in unloading conditions of sandstone after high-temperature treatment," Rock Mechanics and Rock Engineering, vol. 49, no. 7, pp. 2641-2653, 2016.

[56] Q.-L. Ding, F. Ju, S.-B. Song, B.-Y. Yu, and D. Ma, "An experimental study of fractured sandstone permeability after hightemperature treatment under different confining pressures," Journal of Natural Gas Science and Engineering, vol. 34, pp. 5563, 2016.

[57] D. M. Freire-Lista, R. Fort, and M. J. Varas-Muriel, "Freezethaw fracturing in building granites," Cold Regions Science and Technology, vol. 113, pp. 40-51, 2015.

[58] A. Jamshidi, M. R. Nikudel, and M. Khamehchiyan, "Predicting the long-term durability of building stones against freezethaw using a decay function model," Cold Regions Science and Technology, vol. 92, pp. 29-36, 2013.

[59] M. You, C. Su, and X. Li, "Study on relation between mechanical properties and longitudinal wave velocities for damaged rock samples," Chinese Journal of Rock Mechanics and Engineering, vol. 27, no. 3, pp. 458-467, 2008.

[60] M. Q. You, Mechanical Properties of Rocks, Geological Publishing House, Beijing, China, 2007. 

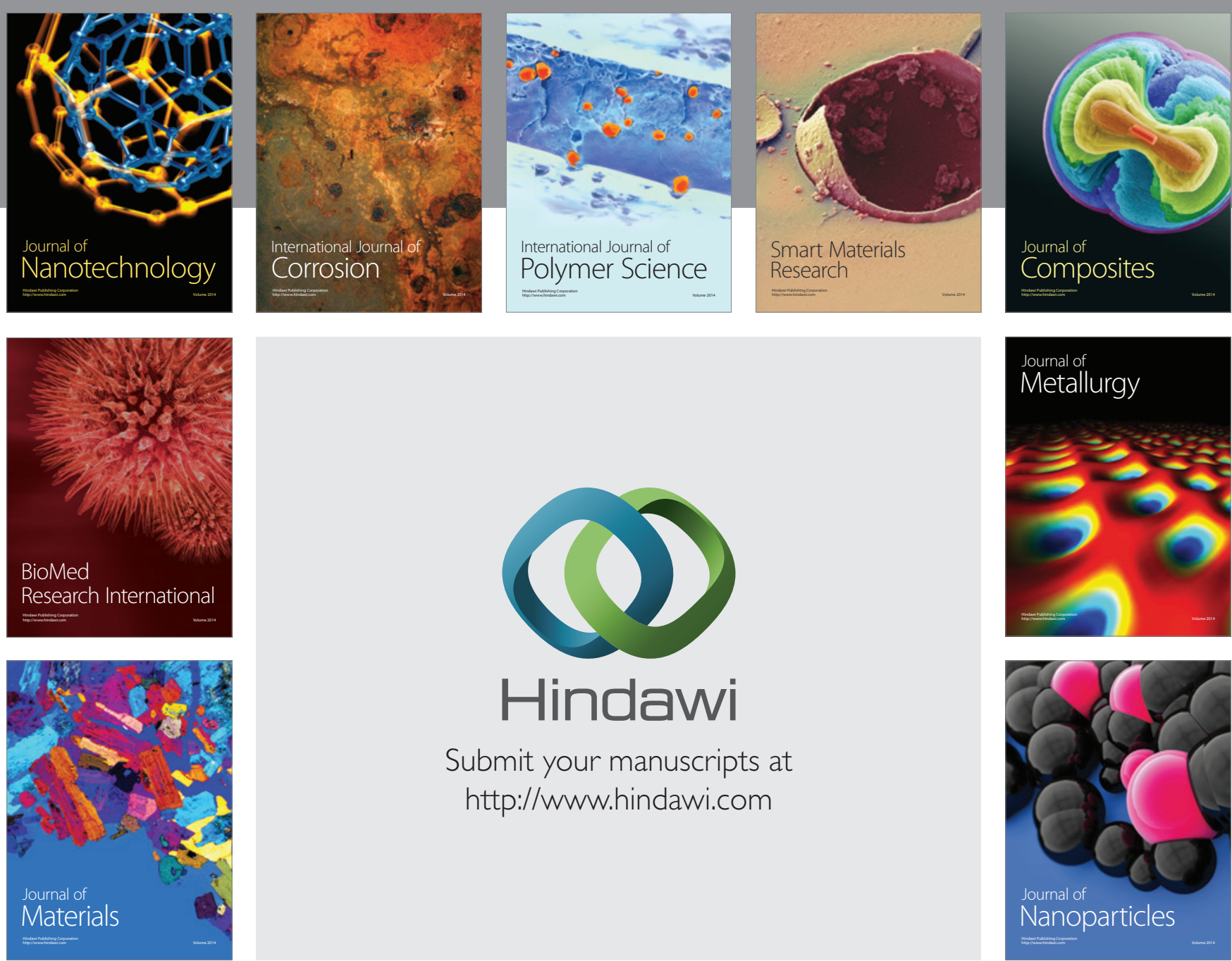

\section{Hindawi}

Submit your manuscripts at

http://www.hindawi.com

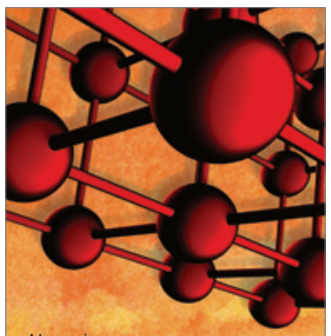

Materials Science and Engineering
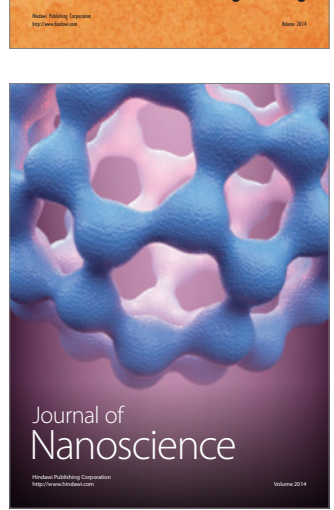
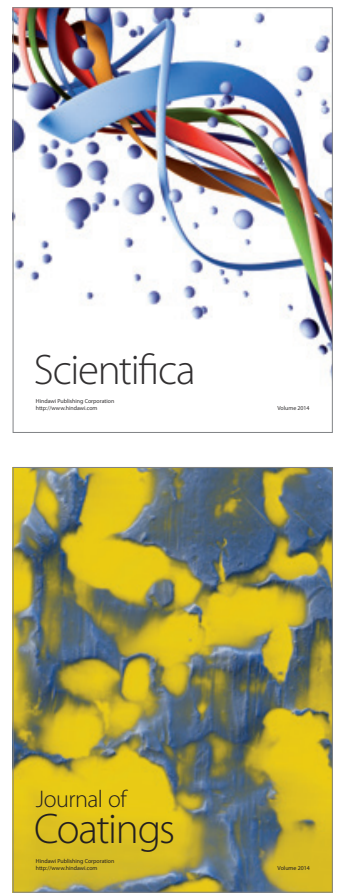
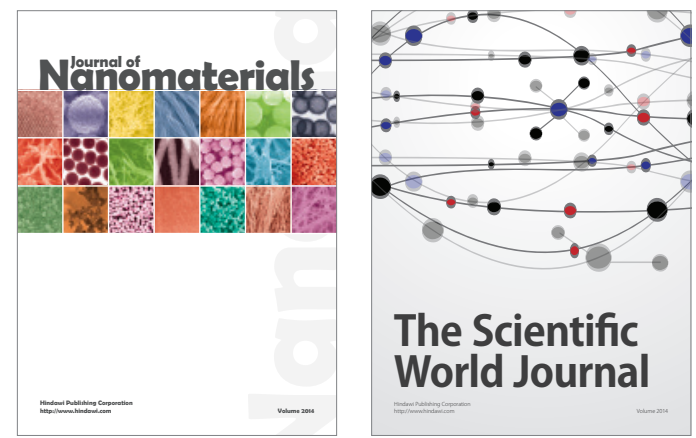

The Scientific World Journal
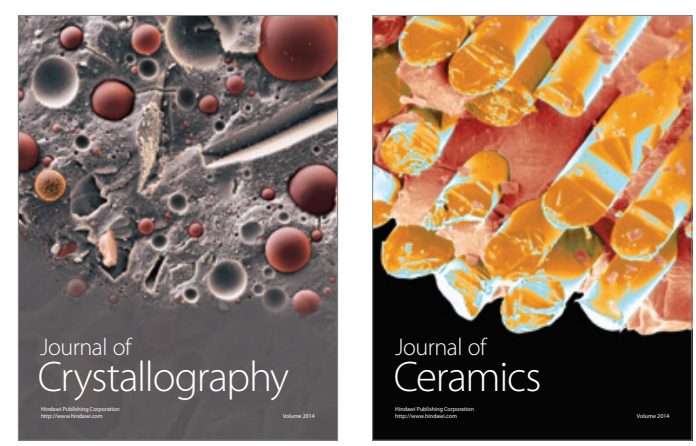
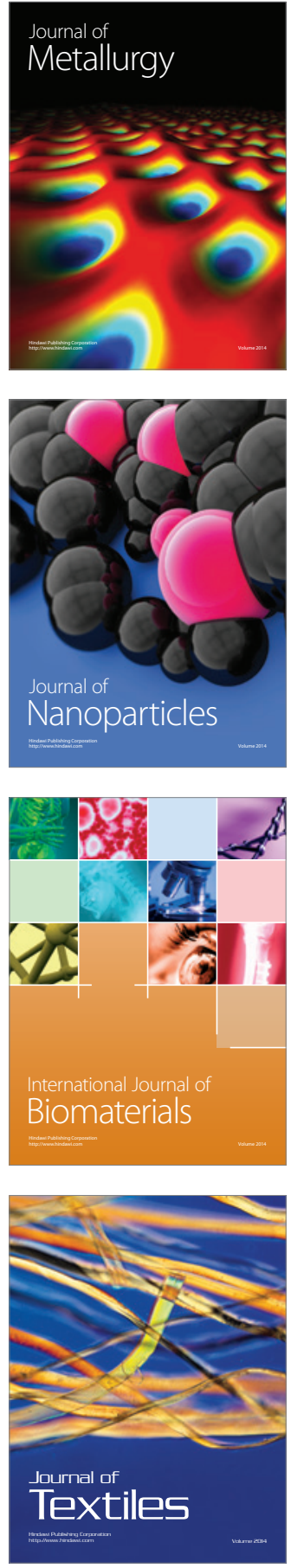